the end of NATO as a cooperative defence organization even though the treaty will not be torn up.) Second, Clinton seems of a temperament to relish appeals to the American people over the heads of Congress. There will probably be a lot of that in the months to come.

\section{Science in schools}

\section{British arguments about the amount of time for science in schools should instead be about the quality of teaching.}

THE research establishment in Britain has reacted ambivalently to the publication last week of the latest (and, it must be hoped) the last version of the national curriculum for the education of young people of 16 and younger. Some regret that it will be possible for young people to emerge from secondary schools (which they may quit, if they choose, at 16) while having studied a form of combined science course for only ten per cent of the time they have spent in classrooms, and have been urging that school students should be persuaded to elect for the double dose of science which is an option under the scheme. Others, by contrast, are plainly relieved that science will remain a part of everybody's education (see page 211). Both opinions miss the realities of secondary school education as it has become.

The reality of modern life in most modern countries is that secondary education is a general education, a preparation for adult life, but not for a particular career. That is how it should be. The core of the government's national curriculum, compulsory for all students, consists of English, mathematics and science, which again is right and proper. But there also has to be time in the school day for young people to learn all the other things they will need to know about as adults, history, foreign languages and music among other things.

Arguments about the proportion of the time that should be spent on science studies is irrelevant. What matters is that all young people should understand something of the nature of scientific inquiry, that they should appreciate its potentially vast scope and that they should acquire a respect for the process. The national curriculum, which is merely a printed document, will not ensure that for all school students, nor will the evaluations and the examinations that accompany it. Everything will depend on the school the students attend and the teachers they find there. It must be hoped that, with the dust now settling, the quality of teaching will improve.

What does that mean for the recruitment of people to the research professions? Nothing, which is how it should be. It is ridiculous to pretend, as some do, that what students learn in the early years of secondary schooling is relevant to their preparation for a career in research, except that bad teaching has the negative effect of turning young people's interests in other directions. Of course, good schools will increasingly be aware that what their students do outside the bounds of the national curriculum may have an important bearing on their futures, in music or in mathematics, but that is again to say that schools matter more than the formal curriculum.

\section{Russia's backward step}

The Russian government is about to institutionalize applied research disastrously.

THE Russian government seems about to make a classic mistake in the administration of science. The report on page 208 that a decree has been signed in conditions of some secrecy for the creation of an academy of applied science is ominous, notably for the people of Russia and for the eventual well-being of Russian industry. The plan seems to be that there will be an academy modelled on, and under the tutelage of, the Russian Academy of Sciences, which will finance and otherwise regulate the myriad research establishments operated by ex-Soviet ministries (including the military establishments). The recipe now being contemplated has all the makings of disaster.

Nobody, of course, denies that there is a problem. The former Soviet Union used to claim that it employed about 4 million people in research establishments, roughly the establishment of the Red Army at its peak. The workforce of the Academy of Sciences was a comparatively small part of the total, probably less than 5 per cent. Since 1987, it has been plain that most of these research workers and their attendants were surplus to any reasonable requirement. Worse than that, even when the applied research establishments were reasonably well equipped, they were constitutionally wrongly sited. The whole world except Russia seems to know that applied research, intended to be helpful to industry, is best planned by individual industrial enterprises and carried out close to and preferably inside the perimeter fences of the relevant industrial plants.

It is an act of madness that the Russian government should now be thinking of perpetuating the old organization, but with the added handicap that the staid forms and organizations of the Russian Academy of Sciences should be grafted onto them. The immediate need appears to offer some security to the people concerned, as well as to invent research programmes on which they can be engaged. No doubt there will be no shortage of schemes on which work could begin quite soon, when the funds for equipment and the like have been raised. But who can have confidence that the programmes will yield results of value to Russian industry, let alone that they will be worthwhile in a more abstract sense?

The long-term price that Russia will have to pay for this new arrangement is even greater. The indifference of working industry to the benefits of research, everywhere apparent, have nowhere been as conspicuous as in Russia. Stalin's Soviet Union specialized in the manufacture of goods and machines that were glaringly inappropriate to the needs of those who would use them. And despite the care spent on the design and monitoring of applied research programmes, Russian civilian industry has mostly been conspicuous for its backwardness in innovation. To institutionalize a system that will perpetuate that state of affairs is at best a folly. When President Boris Yeltsin gets to hear of this decree, he should tear it up. 